\title{
Chemically Modified Polymeric Solid Support for Chromium(III) Speciation in Industrially Polluted Water Samples and Determination by FI-FAAS
}

\author{
Niharika Sharma, Shelja Tiwari, and Reena Saxena* \\ Department of Chemistry, Kirori Mal College, \\ University of Delhi, Delhi - 110007, India
}

\section{INTRODUCTION}

The essentiality and non-essentiality of metals for the functioning of living systems has made it necessary to monitor their abundance and composition in biological and environmental samples. Escalating industrial activities have resulted in pollution by metal toxicants and their accumulation in natural systems, most of which become harmful if present above trace concentrations. In this context, chromium (Cr) is a metal of considerable interest since its toxicological behavior is dependent on the oxidation states it exists in (1), mainly in the trivalent and hexavalent forms. While Cr(III) is naturally present in mineral ores, soils, and waters, $\mathrm{Cr}(\mathrm{VI})$ is rarely ever found to occur naturally. However, Cr(VI) has been reported in natural water systems, a possible explanation being that $\mathrm{Cr}$ (III) is converted to $\mathrm{Cr}(\mathrm{VI})$ under highly oxidizing conditions, such as in the presence of manganese oxides $(2,3)$. Due to the application of chromium in various industries such as metallurgical, refractory, and chemical (pigments, electroplating, tanning), large quantities of chromium-rich waste are released into the environment, leading to an increase in its total concentration in water bodies (4). International regulatory authorities such as the World Health Organization (WHO) consider not more than $0.05 \mathrm{mg} \mathrm{L}^{-1}$ of total chromium in water as an acceptable limit (5). A number of studies have shown that $\mathrm{Cr}(\mathrm{VI})$ induces oxidative stress, DNA damage, apoptosis, and is a

*Corresponding autbor.

:E-mail: reenasaxena@kmcollege.ac.in

\section{ABSTRACT}

The rampant dumping of industrial effluents rich in chromium has increased pollution in the natural water bodies. The contrasting bio-toxicity of its two most stable forms, Cr(III) and $\mathrm{Cr}(\mathrm{VI})$, make it essential that they be separated and accurately determined by FI-FAAS when present together. A new chemically modified polymeric solid support, Dowex Optipore L493 functionalized with $\alpha$-picolinic acid, was used for the selective preconcentration of $\mathrm{Cr}(\mathrm{III})$, while $\mathrm{Cr}(\mathrm{VI})$ was determined by reduction to $\mathrm{Cr}$ (III). Singular analytical techniques suffer from low sensitivity and are unable to differentiate between the bio-essential $\mathrm{Cr}$ (III) and carcinogenic Cr(VI) states. Thus, the on-line preconcentration method aims to improve matrix elimination, enhance trace chromium detection limits, and provides faster sampling. The factors influencing Cr(III) preconcentration were optimized for maximum recovery. The chromium preconcentration efficiency in the presence of several matrix ions was studied. For a 100-second preconcentration time, a preconcentration factor of 78 and detection limit of $0.14 \mu \mathrm{g} \mathrm{L}^{-1}$ were obtained The RSD $(n=5)$ was $1.3 \%$. The linearity of the determinations was up to $540 \mu \mathrm{g} \mathrm{L}^{-1}$. Spike recovery studies in real water samples were performed using standard NIST Cr(III) and Cr(VI) solutions, and a recovery of $>95 \%$ was obtained. The proposed method was validated using NIST SRM 1640a Trace Elements in Natural Water. proven human carcinogen. On the other hand, $\mathrm{Cr}$ (III) is considered to be important for proper insulin function, protein, fat, and the carbohydrate metabolism (6). Thus, due to the contrasting properties and bio-toxicity, the speciation and determination of chromium is a challenge of wide analytical interest.

The spectro-analytical techniques available today are capable of directly determining the concentration of chromium in a variety of sample matrices. Some of these, such as flame or electrothermal AAS, inductively coupled plasma optical emission spectrometry (ICPOES), inductively coupled plasma mass spectrometry (ICP-MS), UVVIS spectrometry, and other chromatographic techniques, have been used frequently for chromium determination (7). Flame AAS (FAAS) is a comparatively inexpensive technique which has good detection limits for some metals and also offers ease of operation. However, there are several disadvantages associated with using singular analytical techniques in trace metal determination. Most of these singular techniques suffer from matrix intolerance, insufficient instrumental detection limits, and inability to differentiate between different chemical species of the analyte. Thus, sample pretreatment methods, such as co-precipitation, solvent extraction, cloud point extraction, dispersive liquid-liquid microextraction, single drop microextraction, solid phase extraction (SPE), etc., have to be used to remove interferences due to the matrix and to preconcentrate chromium (8). 
Solid phase extraction (SPE) offers several advantages over other preconcentration techniques such as higher preconcentration factors, better recoveries, reduction in sample/reagent consumption, lower cost, and more scope for coupling to different detection techniques. Solid phase extractants can be modified by physical adsorption or chemical immobilization of desired organic compounds on their surface (9). The speciation of chromium has been carried out using solid sorbents such as chelating resins (10), silica gel (11), alumina (12), nanomaterials (13), biosorbents (14), etc. Polymeric supports, which are chemically modified by introduction of some organic groups on their surface, are known as chelating solid phase materials. These chemically modified solid supports are better than physically modified supports as the immobilized chelating agent does not leach out during sample elution (15). Also, the chelating resin is found to have higher selectivity for the analyte of interest than an unmodified polymer. However, there are several drawbacks associated with the batch/off-line solid phase extraction (SPE). Both the preconcentration and the analytical steps have to be performed manually; hence, the risk of analyte loss and contamination is unavoidable. Due to this reason, the resulting reproducibility is negatively affected and the sampling frequency $\left(\right.$ samples $\mathrm{h}^{-1}$ ) is also lowered. The hyphenation of a flow injection (FI) system with a detection technique such as FAAS (FI-FAAS) is beneficial as it ensures simultaneous preconcentration and determination of the analyte, while lowering the sample volume and the time consumed per analytical run. So far, chelating resins have been extensively applied in FI-FAAS preconcentration and determination of important heavy metals such as cadmium (16), lead (17), copper and zinc (18) as well as in chromium specia- tion (19). In the present work, Dowex Optipore L493 (commercially available polystyrenic resin) has been chemically modified with $\alpha$-picolinic acid which is a known complexing agent for $\mathrm{Cr}$ (III) (20). The modified resin was used in a SPE method based on FI-FAAS for the speciation and determination of chromium in water samples potentially contaminated due to industrial activities.

\section{EXPERIMENTAL}

\section{Instrumentation}

The flow injection-FAAS hyphenated assembly consisted of a PerkinElmer ${ }^{\circledR}$ FIAS-400 flow injection system and a PerkinElmer ${ }^{\circledR}$ AAnalyst $^{\mathrm{TM}} 400$ FAAS, which was controlled by a personal computer running the WinLab32 $2^{\mathrm{TM}}$ (version 6.5.0.0266) application software (PerkinElmer, Inc., Shelton, CT, USA). The FIAS system consisted of two peristaltic pumps, a five-port two-injection position valve, and a mini-column for preconcentration. The operating conditions of the FI-FAAS system are given in Table I. The FIAS was coupled to the FAAS instrument by connecting the outlet of the FIAS to the FAAS nebulizer using a PTFE tube of suit-

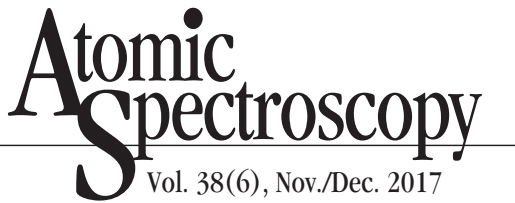

able dimensions. The tubing in the flow system was made of Tygon ${ }^{\circledR}$ and PTFE materials. FT-IR analysis was performed using a Spectrum RX-1 spectrometer (PerkinElmer, Inc., Shelton, CT, USA). The SEM images were obtained using FEI Quanta 200F scanning electron microscope (ICON Analytical, India). The $\mathrm{pH}$ of the solutions was monitored and adjusted using the pH meter model LI-614 (ELICO, India).

\section{Reagents and Materials}

All chemicals and reagents used were of analytical reagent grade and applied without further purification. The standards were prepared by dilution of appropriate volumes of the standard of 1000 $\mathrm{mg} \mathrm{L}^{-1} \mathrm{Cr}$ (III) and $\mathrm{Cr}(\mathrm{VI})$ solutions (Fluka) traceable to NIST. All dilutions were carried out using ultrapure water. Dowex Optipore L493 was obtained from Sigma-Aldrich and was used as the solid polymeric support for further functionalization with $\alpha$-picolinic acid (Thomas Baker). $0.1 \mathrm{~mol} \mathrm{~L}^{-1} \mathrm{HCl}$ solution and phosphate buffer solutions in the $\mathrm{pH}$ range of 6-8 and 9-12 were used for $\mathrm{pH}$ adjustment of the solutions. The polypropylene apparatus (POLYLAB), pre-cleaned with 10\%

TABLE I

Operating Conditions of Flow Injection-FAAS

\begin{tabular}{ll}
\hline Parameters & Recommended Conditions \\
\hline FAAS & PerkinElmer $^{\circledR}$ AAnalyst $^{\mathrm{TM}}$ 400 FAAS \\
Air flow rate & $3.46 \mathrm{~L} \mathrm{~min}^{-1}$ \\
Acetylene flow rate & $9.56 \mathrm{~L} \mathrm{~min}^{-1}$ \\
Lamp specifications & Chromium HCL, Lumina, PerkinElmer, Inc. \\
Lamp current & $10.0 \mathrm{~mA}$ \\
Wavelength & $357.9 \mathrm{~nm}$ \\
Slit/width & $2.7 / 0.8 \mathrm{~mm}$ \\
Flow injection system & PerkinElmer ${ }^{\circledR}$ FIAS-400 \\
Sample injection & Pump P1 \\
Eluent injection & Pump P2 \\
Sample flow rate & $6.0 \mathrm{~mL} \mathrm{~min}{ }^{-1}$ \\
Eluent flow rate & $5.0 \mathrm{~mL} \mathrm{m^{-1 }}$ \\
\hline
\end{tabular}




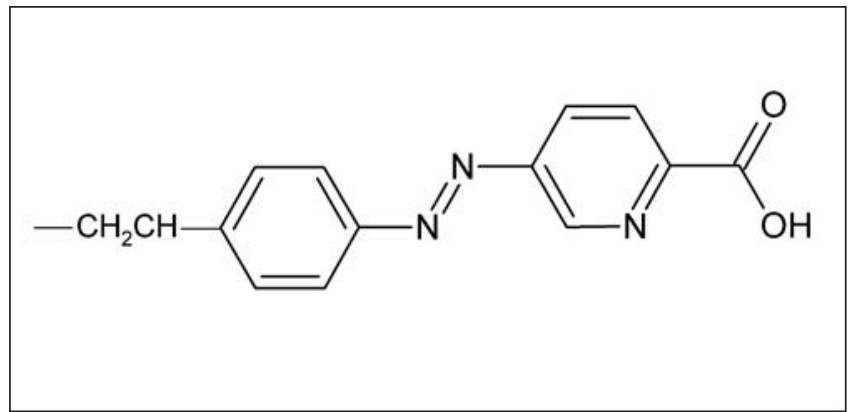

Fig. 1. Proposed structure of PA-493 chelating resin.

$\mathrm{HNO}_{3}$ and ultrapure water, was used for storing all solutions.

Synthesis of Dowex Optipore L493 Immobilized With $\alpha$-Picolinic Acid (PA-493) Chelating Resin

The chemical immobilization of $\alpha$-picolinic acid on Dowex Optipore $\mathrm{L} 493$ polymeric resin was carried out by a modified multi-step synthetic procedure (21). Dowex Optipore L493 was nitrated and then reduced to its amine with stannous chloride. The reduced resin was diazotized, filtered, and washed with cold water, followed by its immediate coupling with ethanolic solution of $\alpha$-picolinic acid in ice cold water for 15 minutes. These modified resin beads were filtered and washed thoroughly with ultrapure water. The obtained resin was air-dried and then stored in a desiccator until use. The proposed structure of the PA-493 chelating resin is given in Figure 1.

\section{Preparation of Minicolumn}

A glass minicolumn with dimensions of $3.0 \mathrm{~cm}$ length $\times 3.0 \mathrm{~mm}$ i.d. was packed with the synthesized chelating resin with the help of a syringe. The ends of the minicolumn were sealed with cotton wool to hold the resin. Prior to first use, the minicolumn was rinsed with $2.0 \mathrm{~mol} \mathrm{~L}^{-1} \mathrm{HNO}_{3}$, followed by ultrapure water.

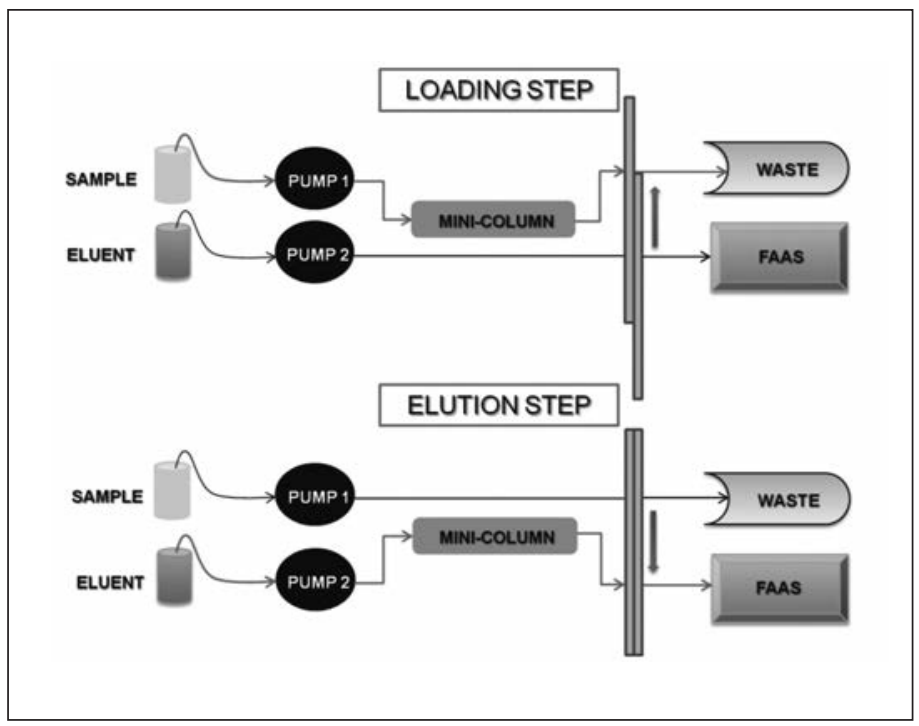

Fig. 2. Flow-injection preconcentration system based on on-line FAAS.

TABLE II

Computer Program for Flow Injection Cr(III) Preconcentration and FAAS Determination

\begin{tabular}{lccccc}
\hline Steps & Time (s) & Pump 1 & Pump 2 & Valve Position & Reading \\
\hline Prefill & 1 & + & + & Elute & - \\
1 & 10 & + & - & Load & - \\
2 & 20 & - & + & Elute & - \\
3 & 40 & + & - & Load & - \\
4 & 10 & + & + & Load & - \\
5 & 30 & - & + & Elute & + \\
\hline
\end{tabular}

Flow-Injection Preconcentration Procedure for Cr(III)

The FI-FAAS preconcentration and determination of $\mathrm{Cr}$ (III) was carried out using the computer program as given in Table II. The program consists of four steps. The first step is the prefill step which triggers the start of the program, followed by the filling steps which ensure the filling of the sample and eluent tubes with their respective solutions. In the 50-second loading step, pump (P1) pumps the sample solution through the minicolumn and the preconcentration of Cr(III) takes place on the chelating resin. In the 30-second elution step, the eluent solution is pumped through the mini-column by pump (P2), thus desorbing the preconcentrated Cr(III) ions from the mini-column while simultaneously carrying it to the nebulizer of the FAAS for detection. The schematic of the FI-FAAS system is represented in Figure 2. Peak height/absorbance is recorded as the analytical signal. A blank measurement was recorded and saved before analysis. For all standard and unknown samples, triplicate measurements were recorded. The operating conditions of the FI-FAAS system are listed in Table I.

\section{Chromium Determination in Real Water Samples}

The water samples were collected from the Yamuna River and three industrially contaminated 
sites in Delhi, India. The collected water samples were acidified using concentrated $\mathrm{HNO}_{3}$, and stored in polypropylene bottles. $25 \mathrm{~mL}$ of each water sample was filtered through a $0.45-\mu \mathrm{m}$ pore size filter paper (Merck Millipore) before the determination of $\mathrm{Cr}$ (III) using the optimized procedure. The spike recovery tests were carried out using $\mathrm{Cr}$ (III) and $\mathrm{Cr}(\mathrm{VI})$ standards traceable to NIST. The determination of Cr(VI) was carried out as described in a previous work (22) by reduction to $\mathrm{Cr}$ (III). From this, the $\mathrm{Cr}(\mathrm{VI})$ concentration could be determined by subtraction from total chromium concentration.

\section{RESULTS AND DISCUSSION}

\section{Characterization of PA-493 Chelating Resin}

FT-IR

The IR spectrum of PA-493 resin (Figure 3a) showed bands at 3452 $(\mathrm{O}-\mathrm{H}), 2974(\mathrm{C}-\mathrm{H}), 1710(\mathrm{C}=\mathrm{O})$, $1628(\mathrm{C}=\mathrm{N}), 1533(\mathrm{~N}=\mathrm{N}), 1275$ $(\mathrm{C}-\mathrm{N})$, and $1238 \mathrm{~cm}^{-1}(\mathrm{C}-\mathrm{O})$. The presence of the stretching bands of $\mathrm{N}=\mathrm{N}, \mathrm{C}=\mathrm{N}$, and $\mathrm{C}-\mathrm{N}$ support the immobilization of $\alpha$-picolinic acid onto Dowex Optipore L-493 through the $\mathrm{N}=\mathrm{N}$ spacer group.
The IR spectrum of the resin saturated with $\mathrm{Cr}$ (III) showed bands at $1702(\mathrm{C}=\mathrm{O}), 1615(\mathrm{C}=\mathrm{N}), 1254$ $(\mathrm{C}-\mathrm{N})$, and $1225 \mathrm{~cm}^{-1}(\mathrm{C}-\mathrm{O})$. These bands were found to be shifted by $\sim 15-20 \mathrm{~cm}^{-1}$ in comparison to the same bands of the unused resin. Also, new bands at 545 and 470 $\mathrm{cm}^{-1}$ corresponding to the $\mathrm{Cr}-\mathrm{O}$ and $\mathrm{Cr}-\mathrm{N}$ stretching vibrations, respectively, were observed (Figure $3 b)$. These observations confirm that the sorption of $\mathrm{Cr}$ (III) by the resin takes place via chelation to the $\mathrm{O}$ and $\mathrm{N}$ atoms of $\alpha$-picolinic acid.

\section{Surface Morphology}

The surface of the unmodified Dowex Optipore L493 resin and PA-493 chelating resin was studied using scanning electron microscopy. The images show that the unmodified resin has a smooth surface structure, whereas the chelating resin has a dense and coarse structure with larger grains (Figure 4). Thus, these differences in the surface structures support the immobilization of $\alpha$-picolinic acid onto Dowex Optipore L493.

\section{Atomic \\ Vol. 38(6), Nov./Dec. 2017}

\section{Optimization of Variables for Cr(III) Preconcentration}

The effective preconcentration of $\mathrm{Cr}$ (III) is influenced by different hydrodynamic and chemical variables. The effect of these variables on the Cr(III) preconcentration and their optimization has been described in this section. The $\mathrm{pH}$ and flow rate of the sample affect the sorption of $\mathrm{Cr}(\mathrm{III})$ onto the chelating resin, whereas the concentration and flow rate of the eluent affect the desorption of Cr(III). Thus, to maximize the preconcentration of Cr(III) using the PA-493 chelating resin, these variables were optimized as given below.

\section{Effect of Sample Acidity}

The $\mathrm{pH}$ of the sample containing Cr(III) affects its sorption on the chelating resin, and thus the optimum $\mathrm{pH}$ for the Cr(III) preconcentration was studied in the $\mathrm{pH}$ range of 2-10. Maximum absorbance was obtained at $\mathrm{pH} 6$ as shown in Figure $5 \mathrm{a}$, which means that maximum Cr(III) sorption took place at this $\mathrm{pH}$. Thus, $\mathrm{pH} 6$ was chosen as the optimum $\mathrm{pH}$ for all subsequent studies.

\section{Choice of Eluent}

The type and concentration of eluent influences the desorption of Cr(III) from the mini-column. Thus, different eluents $(\mathrm{NaOH}, \mathrm{HCl}$, $\mathrm{HNO}_{3}, \mathrm{H}_{2} \mathrm{SO}_{4}$ ), each at $2 \mathrm{~mol} \mathrm{~L}^{-1}$ in

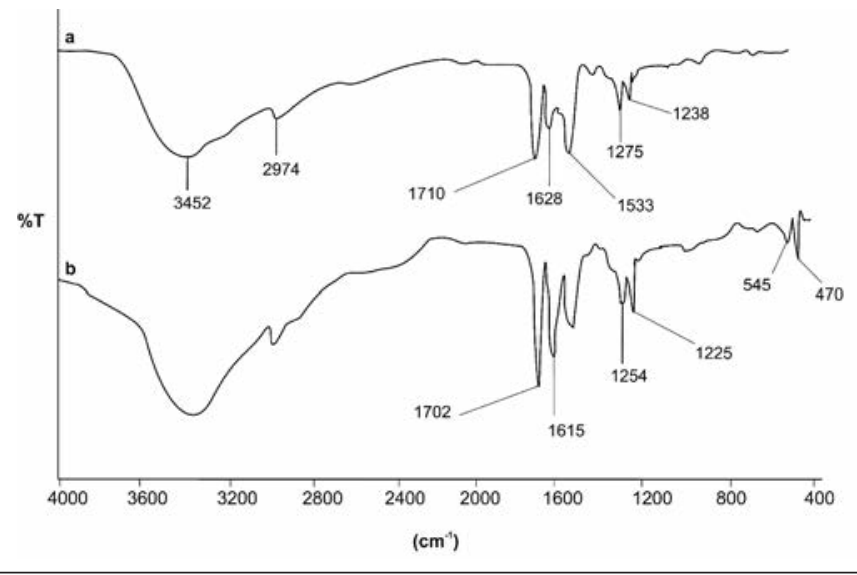

Fig. 3. FT-IR spectra of (a), Dowex Optipore L-493 modified with $\alpha$-picolinic acid (PA-493), and (b), chelating resin saturated with Cr(III).

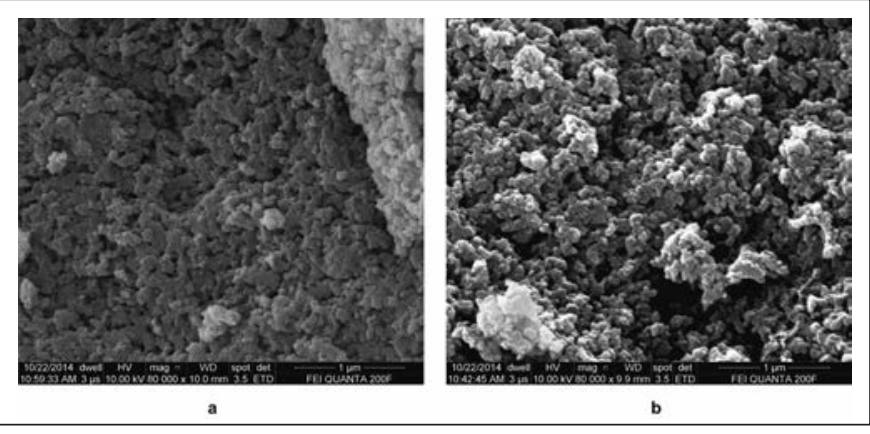

Fig. 4. SEM images of (a) Dowex Optipore L-493, and (b) PA-493 chelating resin. 
concentration, were used to study the optimum $\mathrm{Cr}$ (III) desorption. The most reproducible signals were achieved using $\mathrm{HCl}$ as the eluent. Thus, different concentrations of $\mathrm{HCl}$, ranging between 0.01-2.0 mol L ${ }^{-1}$, were investigated. It was found that maximum $\mathrm{Cr}$ (III) was recovered using $0.2 \mathrm{~mol} \mathrm{~L}^{-1} \mathrm{HCl}$, and the absorbance signals decreased on further increase in the concentration (Figure 5b). Thus, $0.2 \mathrm{~mol} \mathrm{~L}^{-1} \mathrm{HCl}$ was chosen as the eluent for further studies.

\section{Sample and Eluent Flow Rate}

The sample and eluent flow rates were studied in the range of 2-7 $\mathrm{mL} \mathrm{min}^{-1}$ to optimize contact time between the solutions and the chelating resin. It was found that maximum absorbance was obtained at the sample flow rate of $6 \mathrm{~mL} \mathrm{\textrm {min } ^ { - 1 }}$ and the eluent flow rate of $5 \mathrm{~mL}$ $\min ^{-1}$, which are represented in Figure 5c and 5d. These optimized flow rates were kept constant for subsequent analyses.

\section{Effect of Commonly Present Matrix Ions}

Some matrix ions in water are considered to be interferents when their presence varies the analytical signal by more than $\pm 5 \%$. Thus, in the presence of some matrix ions commonly found in water samples, the efficiency of $\mathrm{Cr}$ (III) preconcentration was studied. The tolerance limit of $\mathrm{NO}_{3}{ }^{-}, \mathrm{Cl}^{-}$, and $\mathrm{Na}^{+}$was in the range of $10,000-5,000 \mathrm{mg} \mathrm{L}^{-1}$; $\mathrm{I}^{-}, \mathrm{CH}_{3} \mathrm{COO}^{-}$, and $\mathrm{Br}^{-}$in the range of 5,000-1,000 $\mathrm{mg} \mathrm{L}^{-1} ; \mathrm{NH}_{4}^{+}, \mathrm{K}^{+}$, $\mathrm{Pb}^{2+}$ and $\mathrm{SO}_{4}{ }^{2-}$ in the range of 1,000-100 $\mathrm{mg} \mathrm{L}^{-1}$; and $\mathrm{Ca}^{2+}, \mathrm{Cd}^{2+}$, $\mathrm{Zn}^{2+}, \mathrm{Al}^{3+}, \mathrm{Mg}^{2+}$, and $\mathrm{Cu}^{2+}$ below $100 \mathrm{mg} \mathrm{L}^{-1}$.
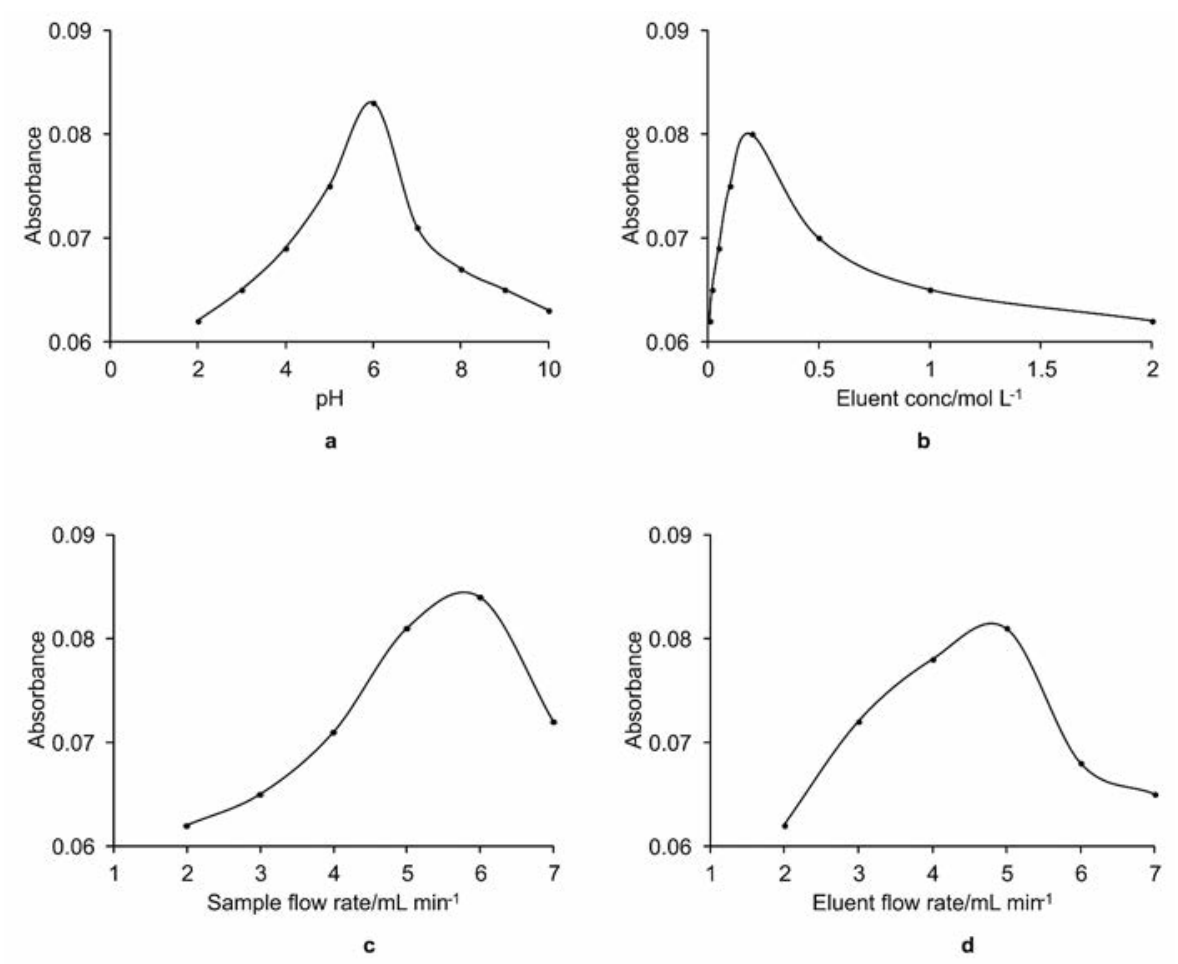

Fig. 5. Optimization of Variables for Cr(III) Preconcentration. (a) Effect of pH, (b) Effect of Eluent Concentration, (c) Effect of Sample Flow Rate, and (d) Effect of Eluent Flow Rate.

\section{Analytical Figures of Merit}

The analytical figures of merit obtained from the proposed method are given in Table III. The preconcentration factor (calculated as the slope of the calibration curve with the preconcentration divided by the slope without preconcentration) was 78 for a 100 -second preconcentration time. The detection limit (calculated as $3 \sigma$ of $n$ replicate measurements of the blank) was found to be $0.14 \mu \mathrm{g} \mathrm{L}^{-1}(n=7)$. Similarly, the limit of quantification (calculated as $10 \sigma$ of $n$ replicate measurements of the blank) was $0.45 \mu \mathrm{g} \mathrm{L}^{-1}(n=7)$. The relative standard deviation reflects the precision of $n$ replicate measurements, and was found to be $1.3 \%$ for 100 $\mu \mathrm{g} \mathrm{L}^{-1}$ of $\mathrm{Cr}(\mathrm{III})$ solution $(n=5)$.

\section{Sorption Capacity of PA-493 Resin}

The chelating resin $\mathrm{PA}-493$ was equilibrated with $50 \mathrm{~mL}$ of $100 \mathrm{mg}$ $\mathrm{L}^{-1}$ of $\mathrm{Cr}$ (III) solution at $\mathrm{pH} 6$ using a mechanical shaker. After 5 hours, the resin was filtered and the filtrate suitably analyzed for Cr(III) concentration using pre-standardized FAAS. The adsorption capacity of the PA-493 chelating resin was calculated to be $28.5 \mathrm{mg} \mathrm{g}^{-1}$, which upon comparison was found to be higher than other reported chelating solid materials (23-29).

\section{Resin Reusability and Column Stability}

A preconcentration cycle consists of subsequent sorption and desorption of Cr(III) from the PA493 resin. After many such cycles, the sorption capacity of the resin was determined as discussed above and compared to that of the unused resin. It was found that there was no appreciable variation in the sorption capacity of the resin, even after 300 - 400 usage cycles. This test shows that the chemical immobilization of a chelating agent onto the polymer surface is stable enough so that the chelating resin 
can be extensively used. Also, the mini-column, once packed, gave steady performance without leakage and was not required to be packed again.

\section{Application to Industrially Polluted Water Samples and Method Validation}

The optimized flow injectionFAAS preconcentration method was applied to river and industrial water samples as described above. The spike tests were carried out to ascertain maximum recovery (>95\%) of chromium from these samples, and recoveries were obtained in the range of $96-100 \%$ (Table IV). The method validation was successfully performed by applying the proposed method to NIST SRM 1640a Trace Elements

TABLE III

Analytical Figures of Merit for Cr(III) Preconcentration

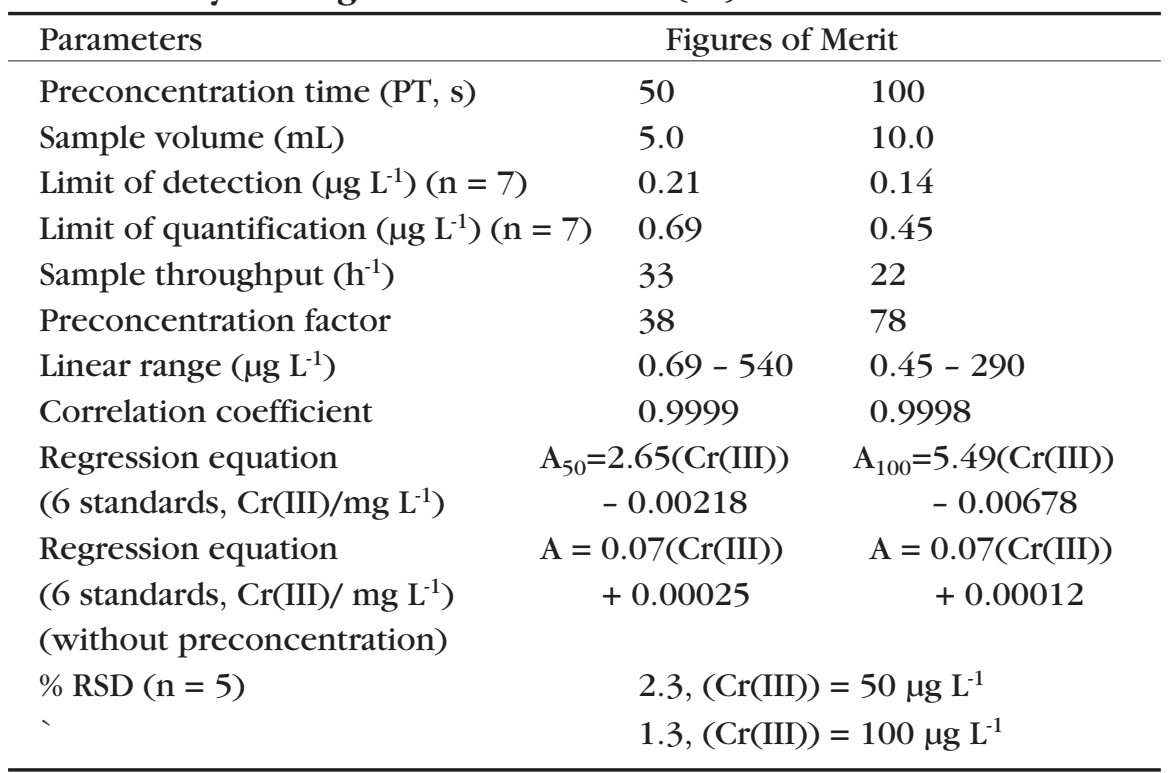

TABLE IV

Analysis of Polluted Real Water Samples Using Proposed Method

\begin{tabular}{|c|c|c|c|c|c|c|c|}
\hline \multirow[t]{2}{*}{ Sample } & \multicolumn{2}{|c|}{ Added $\left(\mu \mathrm{g} \mathrm{L}^{-1}\right)^{\mathrm{a}}$} & \multicolumn{3}{|c|}{ Found $\left(\mu \mathrm{g} \mathrm{L}^{-1}\right)^{\mathrm{b}}$} & \multicolumn{2}{|c|}{ Recovery $(\%)^{\mathrm{b}}$} \\
\hline & Cr(III) & $\mathrm{Cr}(\mathrm{VI})$ & $\mathrm{Cr}(\mathrm{III})$ & $\mathrm{Cr}(\mathrm{VI})$ & Total Cr & $\mathrm{Cr}(\mathrm{III})$ & $\mathrm{Cr}(\mathrm{VI})$ \\
\hline \multicolumn{8}{|c|}{ Anand Parbat Industrial } \\
\hline \multirow[t]{2}{*}{ Area, Delhi, India } & - & - & $25.3 \pm 2.71$ & $10.2 \pm 1.50$ & $35.6 \pm 2.07$ & 97.6 & 99.3 \\
\hline & 20 & 20 & $44.2 \pm 1.35$ & $30.0 \pm 3.51$ & & & \\
\hline \multicolumn{8}{|l|}{ Seelampur Industrial } \\
\hline \multirow[t]{2}{*}{ Area, Delhi, India } & - & - & $22.8 \pm 1.41$ & $6.44 \pm 0.53$ & $29.2 \pm 1.17$ & 97.4 & 97.2 \\
\hline & 20 & 20 & $41.7 \pm 2.88$ & $25.7 \pm 2.51$ & & & \\
\hline \multicolumn{8}{|l|}{ Wazirpur Industrial } \\
\hline \multirow[t]{2}{*}{ Area, Delhi, India } & - & - & $27.4 \pm 1.14$ & $12.5 \pm 3.41$ & $39.9 \pm 2.82$ & 96.8 & 96.9 \\
\hline & 20 & 20 & $45.9 \pm 4.33$ & $31.5 \pm 2.92$ & & & \\
\hline \multicolumn{8}{|l|}{ Yamuna River } \\
\hline \multirow[t]{2}{*}{ Water } & - & - & $37.1 \pm 1.73$ & $26.9 \pm 2.84$ & $64.0 \pm 3.86$ & 100.2 & 96.2 \\
\hline & 20 & 20 & $57.2 \pm 3.61$ & $45.1 \pm 3.43$ & & & \\
\hline
\end{tabular}

${ }^{\text {a }}$ Spiking with $\mathrm{Cr}(\mathrm{III})$ and $\mathrm{Cr}(\mathrm{VI})$ solutions traceable to NIST.

${ }^{\mathrm{b}}$ Confidence Interval 95\%. 
TABLE V

Figures of Merit of Some Reported On-line Cr Preconcentration and Speciation Methods

\begin{tabular}{|c|c|c|c|c|c|c|c|c|}
\hline Support & Chelating Agent & $\begin{array}{l}\text { PT } \\
\text { (s) }\end{array}$ & $\begin{array}{l}\text { Sample } \\
\text { Volume } \\
(\mathrm{mL})\end{array}$ & $\begin{array}{l}\text { Sample } \\
\text { Through- } \\
\text { put }\left(\mathrm{h}^{-1}\right)\end{array}$ & $\begin{array}{l}\text { RSD } \\
(\%)\end{array}$ & DL & $\mathrm{PF}$ & Ref. \\
\hline $\begin{array}{c}\text { Amberlite } \\
\text { XAD-16 }\end{array}$ & Xylenol Orange & 120 & 10 & 20 & 1.1 & 0.11 & 73 & (22) \\
\hline $\begin{array}{l}\text { Divinyl } \\
\text { benzene }\end{array}$ & $\begin{array}{l}\text { Poly 2-(5-methylisoxazol) } \\
\text { methacrylamide-co-2- } \\
\text { acrylamido-2-methyl-1- } \\
\text { propanesulfonic acid }\end{array}$ & 210 & 5.8 & 17 & 2.3 & 0.05 & 48 & $(30)$ \\
\hline Llama Fibers & - & 750 & 25 & - & 4.3 & 0.3 & 32 & (31) \\
\hline MWCNTs & - & 180 & 6 & 16 & 1.7 & 1.15 & 22 & (32) \\
\hline $\begin{array}{l}\text { Nobias chelate } \\
\text { PA-1 }\end{array}$ & - & 120 & 20 & 22 & 3.1 & 1.10 & 49 & (33) \\
\hline S)ilica & $\mathrm{Al}_{2} \mathrm{O}_{3} / \mathrm{TiO}_{2}$ & - & 20 & 21 & 2.4 & 0.66 & 18 & (34) \\
\hline Silica & Niobium(V) oxide & 120 & 15 & 15 & 4.6 & 0.34 & 23 & (35) \\
\hline Silica & Zirconium oxide & 225 & 15 & - & 3 & 1.9 & 21 & (36) \\
\hline UVM-7 & Aminosilane & - & 100 & - & - & 1.2 & 67 & (37) \\
\hline $\begin{array}{l}\text { Dowex } \\
\text { Optipore L493 }\end{array}$ & $\alpha-$ picolinic acid & 100 & 10 & 22 & 1.3 & 0.14 & 78 & This work \\
\hline
\end{tabular}

\section{CONCLUSION}

A rapid and sensitive technique for the speciation and determination of chromium by FI-FAAS in different real water samples has been developed by combining flow injection-based mini-column preconcentration and simultaneous FAAS determination. Dowex Optipore L493 was chemically modified with $\alpha$-picolinic acid and used as the solid phase extractant. The analytical performance of the proposed method was found to be better than other reported on-line chromium speciation methods in terms of sampling frequency, sensitivity (detection limit), preconcentration time and factor. The flow injection system used gave high reproducibility (precision), and the sample volume and time consumption were decreased. The method reports high tolerance for common matrix ions in aqueous samples, and thus effective chromium preconcentration and determination can take place even in highly contaminated samples. The determination of Cr(VI) was made facile via reduction to $\mathrm{Cr}$ (III).

The developed method was validated using NIST SRM 1640a Trace Elements in Natural Water. The recoveries obtained in all experiments on industrial and river water samples were $>95 \%$, which shows that the proposed method is highly selective, sensitive, and reliable for the determination of chromium species. The results also show that due to discharge of untreated industrial wastes, the chromium content in river water has increased beyond the WHO permissible limit. Thus, the developed method can be put to use for selective chromium speciation in a variety of contaminated aqueous matrices.

\section{ACKNOWLEDGMENT}

The authors thank the Department of Science and Technology, New Delhi, India, for providing financial support. The authors are also grateful to the University Sci- ence Instrumentation Center (USIC), University of Delhi, for the FT-IR instrumentation facility and to the SMITA Lab, IIT Delhi, Delhi, India, for SEM facility.

Received June 5, 2017.

\section{REFERENCES}

1. R.A. Mohamed, A.M. Abdel-Lateef, H.H. Mahmoud and A.I. Helal, Studies in Chemical Process Technology (SCPT) 1(4), 75 (2013).

2. A.M. Zayed and N. Terry, Plant Soil 249, 139 (2003).

3. J. Ščančar and R. Milačič, J. Anal. At. Spectrom. 29, 427 (2014).

4. J. Kotaś and Z. Stasicka, Environ. Pollut. 107, 263 (2000).

5. Guidelines for drinking-water quality, 4th ed., World Health Organization, Geneva, Switzerland (2011).

6. D. Bagchi, J.S. Sidney, W.D. Bernard, M. Bagchi and G.P. Harry, Toxicology 180, 5 (2002).

7. R. Rakhunde, L. Deshpande and 


\section{Atomic $_{\text {Spectroscopy }}^{\text {to }}$ \\ 1 Vol. 38(6), Nov./Dec. 2017}

H.D. Juneja, Crit. Rev. Environ. Sci. Technol. 42, 776 (2012).

8. K. Pyrzynska, Int. J. Environ. Anal. Chem. 92(11), 1262 (2012).

9. D. Das, U. Gupta and A.K. Das, Trend. Anal. Chem. 38, 163 (2012).

10. S.Q. Memon, J. Memon, M.I. Bhangera and M.Y. Khuhawar, J. Hazard. Mater. 163, 511 (2009).

11. S. Baytak, A.R. Türker and B.S. Civrimli, J. Sep. Sci. 28, 2482 (2005).

12. D. Das and M. Dutta, Desalin. Water Treat. 51(34-36), 6882 (2013).

13. A. Moghimi, Afr. J. Pure Appl. Chem. 7(4), 146 (2013).

14. P. Smichowski, B. Parodi, G. Polla and L. Valiente, At. Spectrosc. 26(3), 102 (2005).

15. W.A.W. Ibrahim, L.I.A. Ali, A. Sulaiman, M.M. Sanagi and H.Y. Aboul-Enein, Crit. Rev. Anal. Chem. 44, 233 (2014).

16. R. Saxena and S. Singh, Indian J. Chem. 51, 1567 (2012).

17. R. Saxena, S. Saxena and P. Sarojam, At. Spectrosc. 33(3), 83 (2012).

18. R. Saxena and P. L. Meena, RSC Adv. 4, 20216 (2014).

19. N. Sharma, S. Tiwari and R. Saxena, RSC Adv. 6, 10775 (2016).

20. M. Hakimi, J. Korean Chem. Soc. 57(6), 721 (2013).

21. R. Saxena, S. Tiwari and N. Sharma, RSC Adv. 5, 69196 (2015).

22. R. Saxena, N. Sharma and S Tiwari, Anal. Sci. 31, 1303 (2015).

23. Z. Li, X. Chang, Z. Hu, X. Huang, X. Zou, Q. Wu and R. Nie, J. Hazard. Mater. 166, 133 (2009).

24. R.K. Sharma and P. Pant, Int. J. Environ. Anal. Chem. 89, 503 (2009).

25. S. Tiwari, N. Sharma and R. Saxena, New J. Chem. 40, 1412 (2016).

26. M. Tuzen and M. Soylak, J. Hazard. Mater. B129, 266 (2006).

27. S. Vellaichamy and V. Palanivelu, Indian J. Chem. 49A, 882 (2010).
28. P. Liang, Q. Ding and Y. Liu, J. Sep. Sci. 29, 242 (2006).

29. S.H. Ahmadi, A.M.H. Shabani, S. Dadfarnia and M. Taei, Turk. J. Chem. 31, 191 (2007).

30. Ş. Saçmacı, S. Şahan, Ş. Kạrtal, M. Saçmacı, U. Şahin and A. Ülgen, Talanta 120, 391 (2014).

31. R.G. Wuilloud, P.R. Monasterio, J.C. Altamirano and L.D. Martínez, Talanta 77, 1290 (2009).

32. H. Yu, W. Sun, X. Zhu, X. Zhu and J. Wei, Anal. Sci. 28, 1219 (2012).

33. G. Giakisikli, P. Zachariadis, I. Kila, N. Teshima and A. Anthemidis, Anal. Lett. 49(7), 929 (2015).

34. C.R.T. Tarley, G.F. Lima, D.R. Nascimento, A.R.S. Assis, E.S. Ribeiro, K.M. Diniz, M.A. Bezerra and M.G. Segatelli, Talanta 100, 71 (2012).

35. E. Carasek, E. Martendal and H.F. Maltez, J. Hazard. Mater. 161, 450 (2009).

36. E. Carasek and H.F. Maltez, Talanta 65, 537 (2005).

37. H. Shirkhanloo, A. Khaligh, F. Golbabaei, Z. Sadeghi, A. Vahid and A. Rashidi, J. Environ. Health Sci. Eng. 13(47), 1 (2015). 